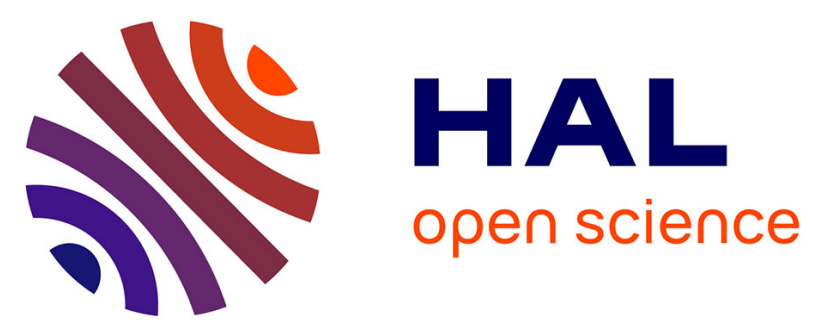

\title{
Trade-off between fracture resistance and translucency of zirconia and lithium-disilicate glass ceramics for monolithic restorations
}

Fei Zhang, Helen Reveron, Benedikt Spies, Bart van Meerbeek, Jérome Chevalier

\section{To cite this version:}

Fei Zhang, Helen Reveron, Benedikt Spies, Bart van Meerbeek, Jérome Chevalier. Trade-off between fracture resistance and translucency of zirconia and lithium-disilicate glass ceramics for monolithic restorations. Acta Biomaterialia, 2019, 91, pp.24-34. 10.1016/j.actbio.2019.04.043 . hal-02395508

\author{
HAL Id: hal-02395508 \\ https://hal.science/hal-02395508
}

Submitted on 22 Oct 2021

HAL is a multi-disciplinary open access archive for the deposit and dissemination of scientific research documents, whether they are published or not. The documents may come from teaching and research institutions in France or abroad, or from public or private research centers.
L'archive ouverte pluridisciplinaire HAL, est destinée au dépôt et à la diffusion de documents scientifiques de niveau recherche, publiés ou non, émanant des établissements d'enseignement et de recherche français ou étrangers, des laboratoires publics ou privés.

\section{(ㄷ)(1) $\$$}

Distributed under a Creative Commons Attribution - NonCommerciall 4.0 International 


\title{
Trade-off between fracture resistance and translucency of zirconia and lithium-disilicate glass ceramics for monolithic restorations
}

Fei Zhang ${ }^{\mathrm{a}}$, Helen Reveron ${ }^{\mathrm{a}}$, Benedikt C. Spies ${ }^{\mathrm{b}}$, Bart Van Meerbeek ${ }^{\mathrm{c}}$, Jérôme Chevalier ${ }^{\mathrm{a} *}$

a. Université de Lyon, INSA-Lyon, MATEIS UMR CNRS 5510, 7 Avenue Jean Capelle, 69621

Villeurbanne Cedex, France

b. Charité - Universitätsmedizin Berlin, corporate member of Freie Universität Berlin, HumboldtUniversität zu Berlin, and Berlin Institute of Health, Department of Prosthodontics, Geriatric

Dentistry and Craniomandibular Disorders, Aßmannshauser Str. 4-6, Berlin, Germany

c. KU Leuven (University of Leuven), Department of Oral Health Sciences, BIOMAT -Biomaterials Research group \& UZ Leuven (University Hospitals Leuven), Dentistry, Kapucijnenvoer 7 blok a, B-3000 Leuven, Belgium

*Email address: jerome.chevalier@insa-lyon.fr

\begin{abstract}
High strength and translucency are generally not coincident in one restorative material and there is still a continuous development for a better balance between these two properties. Zirconia and lithium-disilicate glass-ceramics are currently the most popular alternatives for monolithic restorations. In this work, the mechanical properties and more important, the slow crack growth (SCG) resistance, which rules long-term durability, were thoroughly studied for three zirconia ceramics stabilized by 3,4 and $5 \mathrm{~mol} \%$ yttria in comparison to lithium-disilicate glass-ceramic. Translucency versus strength maps revealed that the more translucent zirconia compositions (i.e. with higher yttria contents) fill the gap between the standard 3 mol\% yttria stabilized zirconia (3YTZP) and lithium-disilicate. Moreover, increasing yttria content did not always result in lower
\end{abstract}


strength, as values for $3 \mathrm{~mol} \%$ and $4 \mathrm{~mol} \%$ yttria were the same. Independent on the yttria contents, all zirconia showed similar relative susceptibility to SCG under static and cyclic conditions and were significantly more SCG-resistant than lithium-disilicate glass ceramic. A concern with higher yttria contents ( 5 and $4 \mathrm{~mol} \%$ ) however could lie in the higher sensitivity to defects, resulting in a larger scatter in strength.

\section{Graphical abstract}
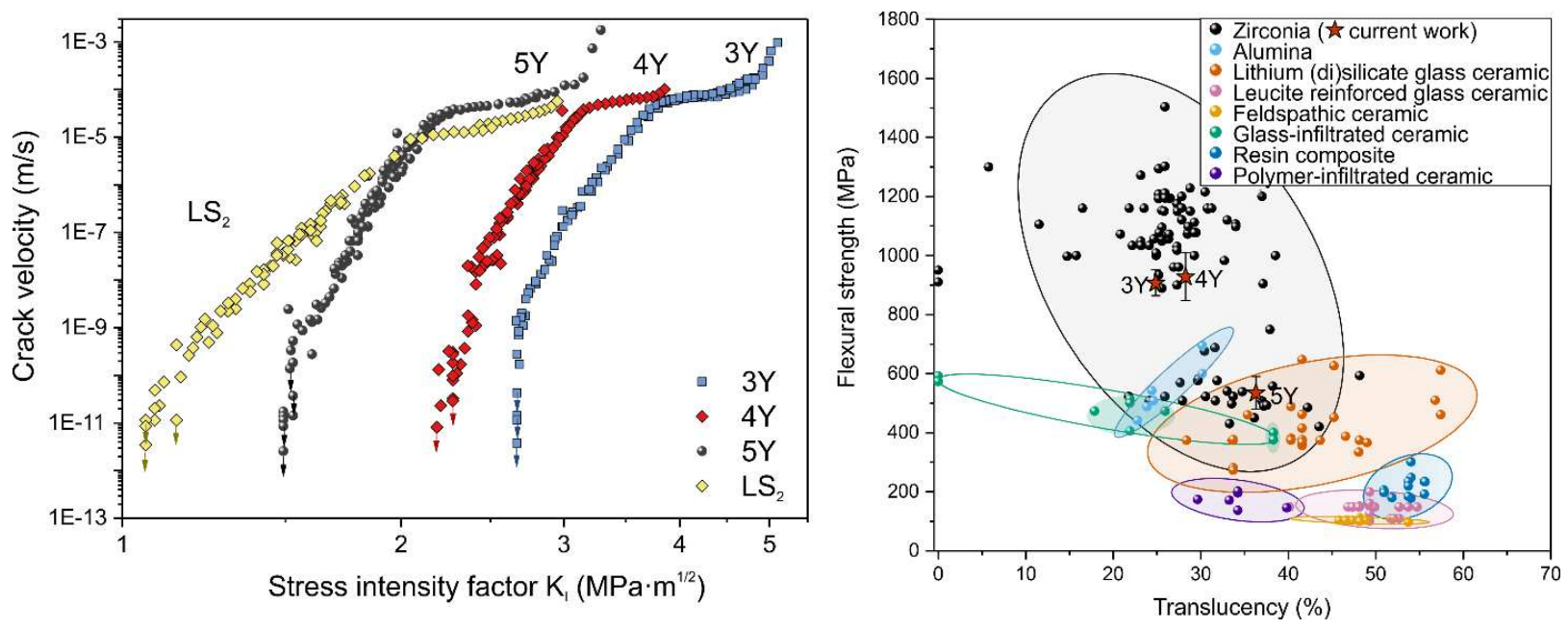

Keywords: Yttria-stabilized zirconia; Monolithic restorations; Slow crack growth; Mechanical properties; Translucency. 


\section{Introduction}

All-ceramic restorations are popularly applied in dentistry, thanks to their excellent biocompatibility and natural appearance as compared to conventional porcelain-fused-to-metal (PFM) crowns and bridges, this together with the benefit of $\mathrm{CAD} / \mathrm{CAM}$ for faster fabrication. Ceramic materials are inherently brittle and vulnerable to crack propagation, which may limit their indication. Zirconia ceramics, in particular 3 mol\% yttria stabilized tetragonal zirconia (3Y-TZP), can however exhibit high strength ( 1000 MPa), which allows the fabrication of long-span fixed dental prosthesis (FDP) in load-bearing areas $[1,2]$. On the other side, most 3Y-TZP are insufficiently translucent and need to be veneered by a quite thick layer of feldspatic porcelain in order to meet the patient's individual tooth characteristics [3]. More recently, there is a clear trend toward monolithic ceramic restorations, avoiding difficulties with the veneering ceramics, i.e. the clinically rather regularly encountered chipping of bi-layered zirconia ceramics, and enabling a less invasive tooth preparation. Monolithic restorations were reported to have become the first choice for posterior teeth in the US since their introduction in 2014 [4]. In order to use ceramics as monolithic restorations with or without a glaze layer, the optical properties of the material itself have to approach that of natural teeth with high translucency being emphasized as one of the primary parameters in controlling optical appearance [5].

3Y-TZP ceramics in general allow less light transmission than glasses or glass-ceramics. Initially, they were even considered as an opaque material [6]. Zirconia doped with 3 mol\% yttria is polycrystalline and mostly in the tetragonal crystallography (which explains the denomination often used of 3 Y-TZP for 3 mol\% Yttria-doped Tetragonal Zirconia Polycrystal). Thus, light scattering occurs at grain boundaries due to birefringence, as well as at residual pores even if present in low percentage. After years of development, many methods have been proposed to improve their translucency, including reduction of porosity acting as light scattering defects or the alumina content, 
using nanostructured zirconia, and very recently increasing the yttria content $[7,8]$. A huge amount of different zirconia ceramics (tetragonal zirconia or TZPs, and partially stabilized zirconia or PSZs) are thus introduced in the dental field and numerous studies report the properties of various hightranslucent zirconia ceramics (Table S1 in supplementary document). Increasing yttria content effectively enhances the translucency of yttria-stabilized zirconia but lowers the strength (less or no phase transformation toughening) $[9,10]$, by which zirconia with a high yttria content can only be used in low stress-bearing areas. However, the current positioning of the newest monolithic zirconia generations in terms of mechanical and optical properties is not clearly and fully defined.

Moreover, few studies have been focused on slow crack-growth behavior and fatigue [11-13], while it is especially important to assess the long-term load-bearing capacity of crack-sensitive ceramics [14]. Standards, solely requiring minimum mechanical properties that are measured under fast fracture conditions (referred to as the inert or initial mechanical strength of the materials [15-17]) should not be considered sufficient for safe use in patients, since the humid environment and cyclic loading in the oral environment can degrade the restoration's load-bearing capacity over time. Chemically-assisted slow crack growth (SCG) occurs due to the presence of water molecules (or other corrosive species, like ammonia or polar solvents), which promote breakage of the strained ionic-covalent bonds at the crack tip, i.e. stress-corrosion reaction, and initiate crack propagation at stress intensities $\left(\mathrm{K}_{\mathrm{I}}\right)$ below the material's fracture toughness $\left(\mathrm{K}_{\mathrm{IC}}\right)$ [18-20]. Cyclic loading induces fatigue in ceramics due to degradation of extrinsic toughening effects [14]. Clinic and lab reports show that dental restorations fail either due to chipping or fracture of the whole structure; such failures often occur at a load far below the initial strength owing to SCG and cyclic fatigue [12, 21]. In particular, in case radial cracks appear at the cementation surface, SCG would very likely reduce the restoration's loading-bearing capability over time [22]. When there is occlusal contact damage at the restoration's surface, cracks can be initiated by cyclic loading and propagate downwards and 
outwards driven by water-assisted SCG (hydraulic pumping), resulting in bulk fractures [21]. Therefore, investigating the fatigue behavior of these new high-translucent zirconia is highly demanded, in particular to determine the threshold stress intensity factor below which no slow crack growth is expected. The threshold parameter was also suggested to be a better predictor than the SCG n parameter for the fatigue and clinical performance of dental ceramics [13].

The aim of this work was to study the crack-growth properties (static and cyclic fatigue) of newly developed zirconia ceramics in combination with a thorough investigation of their strength, mechanical reliability (i.e. scatter in strength values), translucency and microstructures. The results are compared to those of lithium-disilicate glass-ceramic, being another type of popularly used dental ceramics for monolithic restorations. The results are then discussed in the context of the search towards the best compromise between crack resistance and translucency.

\section{Materials and methods}

\subsection{Materials}

Three high-translucent zirconia ceramics were processed from commercially available powders (Zpex, Zpex4 and ZpexSmile, all from Tosoh, Tokyo, Japan). All these powders contain a low percentage $(0.05 \mathrm{wt} \%)$ of $\mathrm{Al}_{2} \mathrm{O}_{3}$. The yttria stabilizer content in Zpex, Zpex4 and ZpexSmile was 3, 4 and $5 \mathrm{~mol} \%$, respectively. The resulting zirconia ceramics were referred to as ' $3 \mathrm{Y}$ ', ' $4 \mathrm{Y}$ ' and ' $5 \mathrm{Y}$ ' throughout the text. Powders were compacted by uniaxial pressing at 40 bar applied on the piston for $40 \mathrm{~s}$ (Nannetti SSN/EA, Faenza (RA), Italy) to disks of $18 \mathrm{~mm}$ in diameter and rectangular plates with surface areas of $30 \times 80 \mathrm{~mm}^{2}$, followed by cold isostatically pressing at $300 \mathrm{MPa}$ for $3 \mathrm{~min}$. Pressed green bodies were debinded following the thermal cycle suggested by the powder supplier, pre-sintered at $1000^{\circ} \mathrm{C}$ for $1 \mathrm{~h}$ and finally pressure-less sintered in air at $1450^{\circ} \mathrm{C}$ for $2 \mathrm{~h}$ using the 
same sintering cycles for all zirconia samples. All materials reached full density of $6.07 \pm 0.01(\mathrm{SD})$, $6.06 \pm 0.01$, and $6.06 \pm 0.00 \mathrm{~g} / \mathrm{cm}^{3}$ for $3 \mathrm{Y}, 4 \mathrm{Y}$ and $5 \mathrm{Y}$, respectively. Sintered disks were used for translucency, microstructural and phase characterizations. Bars for testing 4-point bending strength were cut (Servocut 301-AA, Metkon, Rotterdam, Netherlands) from sintered plates of approx. $22 \times 60 \times 5 \mathrm{~mm}^{3}$ to a size of $5 \times 4 \times 45 \mathrm{~mm}^{3}$ and subsequently machined parallel to their final dimensions of $4 \times 3 \times 45 \mathrm{~mm}^{3}$. The specimens for slow crack growth tests were cut from sintered zirconia plates of approx. $22 \times 60 \times 3 \mathrm{~mm}^{3}$ down to $20 \times 40 \times 3 \mathrm{~mm}^{3}$ and parallel ground to $2 \mathrm{~mm}$ in thickness.

Lithium-disilicate glass ceramic (referred to as ' $\mathrm{LS}_{2}$ ') samples were machined from IPS e.max CAD blocks (IPS e.max CAD HT A2, Ivoclar Vivadent, Schaan, Liechtenstein; 'HT' = high translucency). Plate-shaped specimens were cut from as-delivered blocks of partially crystallized lithium metasilicate precursory phase using a low-speed diamond saw (Accutom-50, Struers, Ballerup, Denmark), followed by crystallization heat treatment according to the manufacturer's instructions in a Programat P300 (Ivoclar Vivadent) vacuum ceramic oven.

\subsection{Material characterization}

X-Ray Diffraction (XRD; 3003-TT, Seifert, Ahrensburg, Germany) was used to characterize the phase composition of sintered ceramics. XRD patterns were collected on as-sintered surfaces using $\mathrm{Cu}-\mathrm{K} \alpha$ radiation at $40 \mathrm{kV}$ and $40 \mathrm{~mA}$ from $20-90^{\circ}(2 \theta)$ with a step size of 0.01 for $3 \mathrm{~s}$. Rietveld analysis of XRD patterns was performed with Topas academic software (Bruker AXS, Karlsruhe, Germany) to quantify phase contents and lattice parameters. Yttria content in the tetragonal zirconia phase was calculated based on the $a$ and $c$ unit cell parameters and the formula previously reported $[10,23,24]$. 
The microstructures were analyzed by Scanning Electron Microscopy (SEM; Supra 40, Carl Zeiss AG, Oberkochen, Germany,) of as-polished ceramic surfaces. Additional surface treatments (thermal and chemical etching, and coating of conductive layer) were avoided in order to observe the intrinsic microstructures of all phases present (crystalline as well as glass phase). The grain size distributions on more than 1000 grains were measured on SEM micrographs according to the linear intercept method without applying any correction factor.

Four-point bending strength was measured at a loading rate of $0.5 \mathrm{~mm} / \mathrm{min}$ with $40 \mathrm{~mm}$ outer span and $20 \mathrm{~mm}$ inner span. Bending bars $(\mathrm{n}=20)$ were sequentially polished with 7, 3, and $1 \mu \mathrm{m}$ diamond pastes prior to the tests. Fracture surfaces obtained by four-point bending testing were examined by SEM.

Translucency was measured on polished specimens $(0.5-\mathrm{mm}$ and $1.0-\mathrm{mm}$ thick; $\mathrm{n}=6$ per group $)$ using a spectrophotometer (SpectroShadeTMMICRO, MHT OpticResearch, Niederhasli, Switzerland). CIELAB coordinates ( $\mathrm{L}^{*}, \mathrm{a}^{*}$ and $\left.\mathrm{b}^{*}\right)$ were recorded against white and black calibrated background boards with a thin layer of vaseline applied in between. Contrast ratio (CR) was calculated, which is 0.0 for a transparent material and 1.0 for a totally opaque material.

\subsection{Slow crack growth}

The double-torsion (DT) method was used to measure crack-growth velocity (V) versus applied stress-intensity factor $\left(\mathrm{K}_{\mathrm{I}}\right)$ curves under static and cyclic conditions at room temperature $\left(\sim 20 \pm 2^{\circ} \mathrm{C}\right)$ in ambient air $(\sim 50 \% \mathrm{RH})$. A wide range of crack-growth velocities from $10^{-12}$ to $10^{-3} \mathrm{~m} / \mathrm{s}$ were followed; the fracture toughness $\left(\mathrm{K}_{\mathrm{IC}}\right)$ associated with fast fracture and threshold $\left(\mathrm{K}_{\mathrm{I} 0}\right)$ below which no crack growth was observed, were determined. Details of the DT loading configuration together with the double-torsion specimens (dimensions of $40 \times 20 \times 2 \mathrm{~mm}^{3}$ for zirconia and $40 \times 18 \times 2$ $\mathrm{mm}^{3}$ for $\mathrm{LS}_{2}$ ) can be found in more details elsewhere $[25,26]$. The tensile surface of the specimens 
was polished to facilitate crack observation. A notch of length 'a0' $(\approx 10 \mathrm{~mm})$ was machined using a 0.3-mm thick diamond sawing blade (ATM GmbH, Mammelzen, Germany). Two 10kg Vickers indentations were made at the tip of notch to initiate a small crack on the tensile side of the sample. Subsequent pre-cracking was performed by slowly loading the specimens at a rate of $10 \mu \mathrm{m} / \mathrm{min}$, so to induce a real sharp crack with an initial length ' $\mathrm{a}_{\mathrm{i}}$ ' $(\approx 12-13 \mathrm{~mm})$ and stable crack front geometry [25].

The $\mathrm{K}_{\mathrm{I}}$ in the double-torsion technique was calculated according to the following expression [18, 26]:

$$
\mathrm{K}_{\mathrm{I}}=\frac{\mathrm{W}_{\mathrm{m}}}{\mathrm{T}^{2}}\left[\frac{3(1+v)}{\mathrm{W} \psi}\right]^{1 / 2} \mathrm{P}\left(\frac{\mathrm{a}}{\mathrm{a}_{0}}\right)^{6 / 32}
$$

where ' $\mathrm{P}$ ' is the load, ' $\mathrm{a}$ ' the total crack length, ' $\mathrm{a} 0$ ' the notch length, ' $\mathrm{W}_{\mathrm{m}}$ ' the span width, ' $\mathrm{T}$ ' the thickness of the sample, ' $\mathrm{W}$ ' the width of the sample, ' $v$ ' the Poisson ratio, and ' $\psi$ ' a calibration factor [27]. Note that $(\mathrm{a} / \mathrm{a} 0)^{6 / 32}$ was the correction factor to conventional expression of $\mathrm{K}_{\mathrm{I}}$, because $\mathrm{K}_{\mathrm{I}}$ was demonstrated to slightly depend on the crack length due to the fact that the crack front was not straight and longer on the tensile side [25].

To obtain the crack-growth curve in full range from threshold to fast fracture, two methods were complementarily used, namely the relaxation and constant test. In the relaxation test that enables measuring the velocity range of $10^{-7}-10^{-2} \mathrm{~m} / \mathrm{s}$, pre-cracked specimens were loaded at the rate of 0.3 $\mathrm{mm} / \mathrm{min}$ to a certain load with the function of load versus time being recorded. The crack velocity (V) for the relaxation test was calculated using the following equation [26, 28]:

$$
V=-\frac{P_{f}}{P^{2}}\left(a_{f}+\frac{D}{B}\right)\left(\frac{d P}{d t}\right)
$$

with ' $a$ ' the final crack length, ' $\mathrm{P}_{f}$ ' the final load, 'dP/dt' the slope of relaxation at a given time, and 'D/B' the constant from the compliance calibration [25]. 
To obtain lower crack rates till near threshold crack rates $\left(10^{-12} \mathrm{~m} / \mathrm{s}\right)$, constant loading tests were used. The specimens were subjected to different loads for a prescribed duration to induce crack extension. The crack length was measured via optical microscopy with a precision of $2 \mu \mathrm{m}$. The crack velocity $(\mathrm{V})$ was calculated as the ratio of the crack increment $(\Delta \mathrm{a})$ to the duration $(\Delta \mathrm{t})$ :

$$
V=\frac{\Delta \mathrm{a}}{\Delta \mathrm{t}}
$$

Crack propagation tests under cyclic conditions were performed under load control using a sine waveform between minimum and maximum load at a ' $\mathrm{R}$ ' $\left(\mathrm{R}=\mathrm{P}_{\min } / \mathrm{P}_{\max }=\mathrm{K}_{\mathrm{I}, \min } / \mathrm{K}_{\mathrm{I}, \max }\right)$ ratio of 0.1 and a frequency of $10 \mathrm{~Hz}$. The maximum load, i.e. the maximum applied stress intensity factor, ' $\mathrm{K}_{\mathrm{I} \text {,max }}$ ' (and also ' $\mathrm{K}_{\mathrm{I}, \mathrm{min}}$ ' to keep $\mathrm{R}=0.1$ ) was lowered until the crack propagation was no longer observed even after loading for 6 days. The crack rate was again determined using Eq. (3) and V$\mathrm{K}_{\mathrm{I}, \mathrm{max}}$ diagrams were obtained for cyclic fatigue. The maximum load used in this work for cyclic fatigue tests was in the range of 95-40 N, bringing $P_{\min }$ of $<10 \mathrm{~N}$ with a negligible effect on the crack velocity.

Known that the $\mathrm{V}-\mathrm{K}_{\mathrm{I}}$ diagram of oxide ceramics generally presents three typical stages in air, attributed to three distinct mechanisms; each stage (Stage I, II, III) of the V-K $\mathrm{K}_{\mathrm{I}}$ diagram can be fitted separately by the form of $\mathrm{V}=\mathrm{A}\left(\mathrm{K}_{\mathrm{I}} \text { or } \mathrm{K}_{\mathrm{I}, \mathrm{max}}\right)^{\mathrm{n}}$, with ' $\mathrm{A}$ ' and ' $\mathrm{n}$ ' being constants that correspond to each stage. Since stage I has a primordial practical importance of ruling the device longevity at the low crack rate, the stress corrosion coefficient/fatigue parameter (n) value from stage I was determined as the slope in the plot of $\ln \left(\mathrm{K}_{\mathrm{I}}\right) \mathrm{vs}$. $\ln (\mathrm{V})$.

In the end, the crack-propagation features were observed by SEM at the crack tip of the surface of DT specimens.

\subsection{Statistical analyses}


One-way analysis of variance (ANOVA) followed by Tukey's post hoc was used to investigate statistical differences in the mean values between different materials at a significance level of $\alpha=$ 0.05 (Minitab ${ }^{\circledR}$ 16.2.1, Minitab Inc, Pennsylvania, USA). The bending strength results were also analyzed by Weibull statistics with confidence bounds $(\alpha=0.05 ; 95 \%$ confidence interval).

\section{Results}

\subsection{Phase characterization}

XRD patterns (Fig.1) showed that all 3Y, 4Y and 5Y zirconia ceramics were composed of mixed tetragonal $\left(t-\mathrm{ZrO}_{2}\right)$ and cubic $\left(c-\mathrm{ZrO}_{2}\right)$ phases. As expected from the $\mathrm{ZrO}_{2}-\mathrm{Y}_{2} \mathrm{O}_{3}$ phase diagram and previous results $[29,30]$, increased yttria content led to higher cubic content at the expense of tetragonal phase. The XRD peaks corresponding to cubic phases in $4 \mathrm{Y}$ and $5 \mathrm{Y}$ can be clearly observed in between the doublet peaks of tetragonal phases (Fig. 1b). Quantification of the XRD patterns by Rietveld analysis (Table 1) revealed the formation of about 40 and $60 \% c-\mathrm{ZrO}_{2}$ in $4 \mathrm{Y}$ and $5 \mathrm{Y}$, respectively, as compared to about $10 \% c-\mathrm{ZrO}_{2}$ in $3 \mathrm{Y}$. In addition, the remaining tetragonal phase in $4 \mathrm{Y}$ and $5 \mathrm{Y}$ contained higher yttria content together with a smaller tetragonality (lower c/a ratio), consistent with current literature [29].

\subsection{Microstructure}

The microstructure of the zirconia ceramics revealed polycrystalline and dense structures with only occasionally very few pores (Fig. 2a). Grain-size distributions were all unimodal (Fig. 2b). The three zirconia ceramics significantly differed in microstructure for grain size (Table 2). On the other side, $\mathrm{LS}_{2}$ consisted of $\mathrm{Li}_{2} \mathrm{Si}_{2} \mathrm{O}_{5}$ crystals (confirmed by XRD) embedded in a glass matrix. The length of the crystals was in the range of $2 \mu \mathrm{m}$ (Table 2) with an aspect ratio of about 4 in respect of their 
diameter. Small pores could be clearly observed in the crystalline and glass phases of the $\mathrm{LS}_{2}$ specimens.

\subsection{Translucency}

At the thickness of 0.5 - and $1.0-\mathrm{mm}$, the translucency of $5 \mathrm{Y}>4 \mathrm{Y}>3 \mathrm{Y}$ and increasing yttria content significantly enhanced the translucency (lower CR) of zirconia ceramics (Table 2). Reducing thickness also increased the translucency of the three zirconia ceramics. Nevertheless, at the same thickness, $\mathrm{LS}_{2}$ HT's translucency remained significantly higher than that of all zirconia ceramics investigated (Fig. 3).

\subsection{Strength}

The average bending strength of 3Y, 4Y and 5Y was 908, 928 and $524 \mathrm{MPa}$, respectively (Table 2). Weibull analysis (Fig. 4a) revealed their characteristic strength $\left(\sigma_{0}\right)$ [95\% C.I.] was 951 [901-1002], 998 [925-1070] and 581 [532-631] MPa, respectively. There was no statistical difference in bending strength between 3Y and 4Y (Table 2). However, a lower Weibull modulus was obtained for 4Y samples. 5Y had an even lower strength and Weibull modulus than $3 \mathrm{Y}$ and 4Y. Fractography of the bending bars (Fig. 4b) were examined in the area close to the fracture origin within the mirror region, since the crack initiated and rapidly accelerated in this region. 3Y and 4Y exhibited similar fracture patterns consisting of mixed intergranular and transgranular fractures with fine zirconia-grain sizes, whereas the fracture surface of $5 \mathrm{Y}$ was different with almost only transgranular fractures through much larger zirconia grains.

Regarding the strength of $\mathrm{LS}_{2}$, the size of available $\mathrm{LS}_{2}$ blocks (max. $40 \mathrm{~mm}$ in length) did not allow performing the 4-point bending test in this work using $40 \mathrm{~mm}$ outer span and also the corresponding 
statistical analysis. The flexural strength of $\mathrm{LS}_{2}$ in Table 2 was thus referred to the value reported by Wendler et al. [31] using the same methodology and the same type of $\mathrm{LS}_{2}$ specimens but smaller dimension. Considering also the previous report showing that the biaxial strength of $5 \mathrm{Y}$ and $\mathrm{LS}_{2}$ were not statistically different [32], the 4-point bending strength of $\mathrm{LS}_{2}$ and $5 \mathrm{Y}$ shown here in Table 2 should be similar or marginally different.

\subsection{Crack-growth resistance}

Under static loading (Fig. 5a), V-K $\mathrm{K}_{\mathrm{I}}$ diagrams were recorded from fast fracture ( $\left.\mathrm{K}_{\mathrm{IC}}\right)$ down to threshold $\left(\mathrm{K}_{\mathrm{I} 0}\right)$ for all ceramics investigated, including for the reference $\mathrm{LS}_{2}$ glass ceramic. The toughness $\left(\mathrm{K}_{\mathrm{IC}}\right)$ was estimated at a high crack velocity of $10^{-3} \mathrm{~m} / \mathrm{s}$ and the threshold $\left(\mathrm{K}_{\mathrm{I} 0}\right)$ was determined from the points below which there was an abrupt drop to a crack velocity of about $10^{-12}$ $\mathrm{m} / \mathrm{s}$ (see Table 3 ). Increasing yttria content clearly shifted the V-K $\mathrm{K}_{\mathrm{I}}$ curve towards lower $\mathrm{K}_{\mathrm{I}}$ values. However, the V-K $\mathrm{K}_{\mathrm{I}}$ curves remained parallel in a log-log scale. Similar $\mathrm{K}_{\mathrm{I} 0} / \mathrm{K}_{\mathrm{IC}}$ values $(\sim 0.5)$ and a stress corrosion coefficient (n) of $\sim 30$ were thus observed for all zirconia ceramics, which revealed a similar relative susceptibility to SCG. When compared to $\mathrm{LS}_{2}, 5 \mathrm{Y}$ and $\mathrm{LS}_{2}$ showed a similar fracture toughness, but the $\mathrm{K}_{\mathrm{I} 0}$ of $\mathrm{LS}_{2}\left(1.1 \mathrm{MPa} \cdot \mathrm{m}^{1 / 2}\right)$ was lower than that of $5 \mathrm{Y}$. Although the difference was only $0.4 \mathrm{MPa} \cdot \mathrm{m}^{1 / 2}$, it represented about $30 \%$ of relative difference. This finding indicated that $\mathrm{LS}_{2}$ was more sensitive to SCG than zirconia ceramics. The $\mathrm{n}$ value of the $\mathrm{V}-\mathrm{K}_{\mathrm{I}}$ curve corresponding to $\mathrm{LS}_{2}$ was indeed lower $(\sim 16)$ and a smaller $\mathrm{K}_{\mathrm{IO}} / \mathrm{K}_{\mathrm{IC}}$ value $(\sim 0.35)$ was recorded.

With respect to the effect of cyclic loading, the cyclic V-K Imax curves of zirconia ceramics are shown in Fig. $5 \mathrm{~b}$ and the comparison to reference $\mathrm{LS}_{2}$ is shown in Fig. 5c. For the three zirconia ceramics, the crack-growth rates under cyclic loading were clearly accelerated compared to static crack growth at equivalent stress intensities. One should also note that cyclic crack-growth rate was presented as 
a function of $\mathrm{K}_{\operatorname{Imax}}$ and that the determination of the exact cyclic degradation from the direct comparison of static $\mathrm{V}-\mathrm{K}_{\mathrm{I}}$ and cyclic $\mathrm{V}-\mathrm{K}_{\mathrm{I}, \max }$ would not be correct. The crack velocity per cycle $\left(\mathrm{da} / \mathrm{dN}-\mathrm{K}_{\operatorname{Imax}}\right)$ if there was no cyclic fatigue degradation can be estimated, as previously reported [18], by an integration of the $\mathrm{V}-\mathrm{K}_{\mathrm{I}}\left(\mathrm{da} / \mathrm{dt}-\mathrm{K}_{\mathrm{I}}\right)$ curve over a cycle. Crack-growth rate per cycle $(\mathrm{da} / \mathrm{dN}-$ $\mathrm{K}_{\mathrm{Imax}}$ ) would have been lower than for static da/dt- $\mathrm{K}_{\mathrm{I}}$, as indicated by the dash line for $3 \mathrm{Y}$ in Fig. 5b. Indeed, since the average integrated load (varying between $\mathrm{P}_{\min }$ and $\mathrm{P}_{\max }$ ) is lower under cyclic loading than $\mathrm{P}_{\max }$, the crack-growth rate would be lower than at a constant maximum load, if no cyclic degradation was present. The real effect of cyclic fatigue degradation is therefore appreciated from the difference between the calculated $\mathrm{V}-\mathrm{K}_{\mathrm{Imax}}$ curve (dashed lines in fig. $5 \mathrm{~b}$ for $3 \mathrm{Y}$-TZP) and the experimental one. Therefore, cyclic loading significantly degraded the crack resistance of the three zirconia ceramics. Regarding the reference $\mathrm{LS}_{2}$ glass ceramic (Fig. 5c), similar to the zirconia ceramics, cyclic degradation was also observed for $\mathrm{LS}_{2}$ : cyclic crack growth occurred at stress intensities below that for static crack growth; $\mathrm{K}_{\mathrm{I} 0}$ was shifted to a lower value and the $\mathrm{V}$ - $\mathrm{K}_{\mathrm{I}, \max }$ curve had a lower slope (Table 3).

Fig. 6 shows SEM images in the vicinity of the crack tips at the surfaces of the DT samples. Unlike metals [14] and because of no (or very localized and limited) plasticity, the crack-propagation modes and microstructures of cyclically and statically loaded specimens did not show differences, so only images obtained from statically loaded specimens were representatively shown. Along the crack path in 3Y, grains at a depth of 1-2 grains were transformed and a twining morphology of monoclinic grains were clearly observed to have arrested the crack opening (as illustrated in the schematic). 4Y revealed a similar behavior as $3 \mathrm{Y}$, but less grains were transformed along the crack path. $5 \mathrm{Y}$, on the other hand, exhibited no transformed grains. Crack bridging at the level of zirconia grains can be found in all zirconia ceramics with however relative straight crack propagation, if we compare with polycrystalline ceramics with larger or more elongated grains [33-35]. Crack deflection and bridging 
were more pronounced for $\mathrm{LS}_{2}$ with clearly meandered crack paths (note also the different scale bar in $\left.\mathrm{LS}_{2}\right)$.

\section{Discussion}

\subsection{Toughening and mechanical properties that are measured at fast fractures}

The toughening mechanisms of the materials in general consist of intrinsic $\left(\mathrm{K}_{0}\right)$ and extrinsic toughening $\left(\Delta \mathrm{K}_{\mathrm{c}}\right)$, and the extrinsic toughening mechanism working in the wake of the crack (i.e. crack-shielding) is known to be the primary toughening sources for brittle ceramic materials [36], by which transformation toughening, crack bridging, crack deflection and/or combinations thereof are relevant toughening mechanism in the four materials investigated [36, 37]. Reduction of phasetransformation toughening from $3 \mathrm{Y}$ to $4 \mathrm{Y}$ and $5 \mathrm{Y}$ (Fig. 6) obviously resulted in the shifts of the V$\mathrm{K}_{\mathrm{I}}$ curve to lower $\mathrm{K}_{\mathrm{I}}$ values with lower $\mathrm{K}_{\mathrm{IC}}$ and $\mathrm{K}_{\mathrm{I} 0}$ (Table 3). In $4 \mathrm{Y}$ and $5 \mathrm{Y}$, not only more nontransformable cubic phase was formed, the remaining tetragonal phase was also less transformable with lower tetragonality (Table 1). $4 \mathrm{Y}$ thus had less toughening effect from phase transformation than $3 \mathrm{Y}$, whereas $5 \mathrm{Y}$ did not show any evidence of phase transformation toughening. Although grain bridging that generally exists in polycrystalline ceramics was present in all zirconia ceramics including $5 Y$ (Fig. 6), this mechanism from fine (0.3-0.5 $\mu$ m, Table 2 and Fig. 6) and equiaxed grains should merely be effective on small dimensions in a limited extent, unlike in the case of coarse-grained $\mathrm{Al}_{2} \mathrm{O}_{3}$ or grain-elongated $\mathrm{Si}_{3} \mathrm{~N}_{4}[14,33-35,38,39]$. Due to the relative large and elongated $\mathrm{Li}_{2} \mathrm{Si}_{2} \mathrm{O}_{5}$ crystals (Fig. 2a) [40, 41], crack deflection and crack bridging was effective in $\mathrm{LS}_{2}$ (Fig. 6).

On the other side, different from the general expectation, $4 \mathrm{Y}$, although being less tough than $3 \mathrm{Y}$, did not show a lower bending strength (Table 2). The high strength of $4 \mathrm{Y}$ should be related to the 
small processing defects and the fine microstructure (Fig. 2). Based on the strength distribution (Table 2) and toughness values (Table 3), the size of critical flaws in $4 \mathrm{Y}$ was calculated to be in the range of 13-9 $\mu \mathrm{m}$, using linear-elastic fracture mechanics and the Griffith equation ( $\mathrm{Y}=1.3)$ [42]. The critical flaw in $3 \mathrm{Y}$ and $5 \mathrm{Y}$ was in the range of $20-17 \mu \mathrm{m}$ and $26-17 \mu \mathrm{m}$, respectively. The grain sizes/distributions (Fig. 2) and facture patterns (Fig. 4b) of 4Y and 3Y were also very close. Another work reported a biaxial strength of higher than $1100 \mathrm{MPa}$ for $4 \mathrm{Y}$, similar to that of $3 \mathrm{Y}$, when using the same sintering cycles [43]. In the work reporting a lower strength of 4Y [32], the grain size of 4Y however was much larger than that of $3 \mathrm{Y}$. Nevertheless, despite the similar strength of $4 \mathrm{Y}$ and $3 \mathrm{Y}$, the strength scatter of $4 \mathrm{Y}(\mathrm{m}=6)$ was higher than for $3 \mathrm{Y}(\mathrm{m}=10)$, followed by an even higher one for 5Y (m=5) (Fig. 4). Decreased mechanical reliability when increasing yttria content should be attributed to the reduced crack-growth resistance and thus higher sensitivity to cracks/defects. At the same time, lower crack resistance raises another concern in terms of surface treatment. Clinically conducted surface treatments, such as sandblasting, are able to enhance the strength of $3 \mathrm{Y}$-TZP thanks to the generated compressive stresses [44], but this effect might be compromised/lost [45] in PSZ (4Y and 5Y).

When comparing to $\mathrm{LS}_{2}$ glass ceramic, $4 \mathrm{Y}$ and $3 \mathrm{Y}$ showed better mechanical properties, but $5 \mathrm{Y}$ revealed only a marginally higher fracture toughness (Table 3) and flexural strength (Table 2) [32]. Importantly, a lower strength scatter, i.e. higher mechanical reliability (m 10 [31, 46-48]) was recorded for $\mathrm{LS}_{2}$ than $5 \mathrm{Y}$. The finding that $\mathrm{LS}_{2}$ and $5 \mathrm{Y}$ have a similar fracture toughness $\left(\mathrm{K}_{\mathrm{IC}}\right)$ but different reliability, should probably be attributed to the different proportions of intrinsic toughness $\left(\mathrm{K}_{0}\right)$ and extrinsic toughening $\left(\Delta \mathrm{K}_{\mathrm{c}}\right)$. As explained at the beginning of the discussion, the $\mathrm{K}_{\mathrm{IC}}$ of brittle materials and more specifically the crack growth resistance $\left(K_{R}\right)$ commonly consists of $K_{0}$ and $\Delta \mathrm{K}_{\mathrm{c}}$, and $\Delta \mathrm{K}_{\mathrm{c}}$ can lead to a stably rising crack resistance, i.e. R-curve behavior [36, 37]. $\mathrm{K}_{0}$ of 
$\mathrm{LS}_{2}$ is reported to be about $1.2 \mathrm{MPa} \cdot \mathrm{m}^{1 / 2}[40]$, whereas $\mathrm{K}_{0}$ of zirconia is around $2 \mathrm{MPa} \cdot \mathrm{m}^{1 / 2}[36,49]$. It can then be figured that $\Delta \mathrm{K}_{\mathrm{c}}$ for $\mathrm{LS}_{2}$ is higher than for $5 \mathrm{Y}$, resulting in a stronger R-curve for $\mathrm{LS}_{2}$ with better tolerance to cracks/defects. Indeed, the most potent extrinsic toughening mechanism (i.e. phase transformation) for zirconia ceramics was absent in $5 \mathrm{Y}$ zirconia, while $\mathrm{LS}_{2}$ had obviously effective extrinsic toughening effect from crack deflection and crack bridging (Fig. 6), contributing to the higher mechanical reliability of $\mathrm{LS}_{2}$. Another similar lithium-disilicate glass-ceramic with elongated $\mathrm{LS}_{2}$ crystals (Empress 2, Ivoclar Vivadent AG) even showed higher Weibull modulus than a $3 Y-T Z P$ ceramic [17]. The microstructure of $\mathrm{LS}_{2}$ investigated here (Fig. 2a) also showed more defects (porosities and heterogeneous structures) than that of 5Y, despite they revealed a similar or marginally different strength.

\subsection{Long-term durability: SCG and cyclic fatigue}

Independent on $\mathrm{K}_{\mathrm{IC}}$ and the yttria content, $3 \mathrm{Y}$, $4 \mathrm{Y}$ and $5 \mathrm{Y}$ showed a similar relative susceptibility to SCG under static loading (parallel shift of V-K $\mathrm{K}_{\mathrm{I}}$ curves in a log-log scale; $\mathrm{K}_{\mathrm{I} 0 \text {,static }} / \mathrm{K}_{\mathrm{IC}} \sim 0.5$; similar stage-I $\mathrm{n}$ value of $\sim 30$ ), yet having a significant higher SCG resistance than $\mathrm{LS}_{2}$ (n of $\sim 16$, $\mathrm{K}_{\mathrm{I} 0 \text {,static }} / \mathrm{K}_{\mathrm{IC}} \sim 0.4$ ) (see Fig. 5a and Table 3). It is necessary to first clarify that the $\mathrm{V}-\mathrm{K}_{\mathrm{I}}$ curves obtained in this work by DT should not be influenced by the R-curve behavior. Although the extrinsic toughening effects and the resulting R-curve behavior were different for the four materials investigated, the steady state conditions of the R-curve should be reached in the crack-size domain of the DT tests. The transformation zone (h) in the studied $3 \mathrm{Y}$ was found to be about $1 \mu \mathrm{m}(1-2$ grains in Fig. 6), revealing that 3Y should reach the R-curve steady status at a crack length of about $5 \mu \mathrm{m}$ (about 5 times the transformation zone [50]). Although the R-curve of $\mathrm{LS}_{2}$ is estimated to be stronger than that of $5 \mathrm{Y}$, a steep raise over the first micrometers or tens of micrometers was also 
reported because of the fine dimensions of $\mathrm{Li}_{2} \mathrm{Si}_{2} \mathrm{O}_{5}$ crystals [13, 41]. In addition, the rising part of R-curve would result in a higher slope of the V-KI curve [33], which is the opposite as observed for $\mathrm{LS}_{2}$. Therefore, the differences in observed SCG susceptibility should not be attributed to the Rcurve but to the material's intrinsic susceptibility to water-assisted stress-corrosion reactions, namely chemically assisted SCG. For the three zirconia ceramics, they are free of glass phase with the same $\mathrm{Zr}-\mathrm{O}-\mathrm{Zr}$ bonds, presenting the same stress corrosion at the crack tip, which has also been observed before for 3Y-TZP with different grain sizes and for zirconia stabilized by different stabilizers [51]. $\mathrm{LS}_{2}$ consists of $70 \mathrm{vol} \% \mathrm{Li}_{2} \mathrm{Si}_{2} \mathrm{O}_{5}$ crystals and $30 \mathrm{vol} \%$ silicate glass phase. It is difficult to quantitatively compare the water affinity of $\mathrm{Zr}-\mathrm{O}$ and $\mathrm{Li}-\mathrm{O} / \mathrm{Si}-\mathrm{O}$ bonds, but (silicate) glass materials are known to be more susceptible to hydrolysis and stress-corrosion than polycrystalline materials $[12,13,52]$. The different SCG susceptibility recorded between zirconia and $\mathrm{LS}_{2}$ (Fig. 5c) is reflected in stage I, confirming the effect of the stress-corrosion reaction.

Regarding the cyclic SCG, all studied ceramics showed cyclic degradation with decreased $\mathrm{K}_{\mathrm{I} 0 \text {,cyclic }}$ and lower slope of $\mathrm{V}-\mathrm{K}_{\mathrm{I} \text {,max }}$. Cyclic fatigue accelerates the crack growth in brittle ceramics by degrading the extent of extrinsic crack-tip shielding toughening [14] that again involves transformation toughening, bridging, deflection and/or combinations thereof (Fig. 6) [14, 36]. Since the extent of extrinsic toughening was not the same for the four studied materials, materials undergoing higher extrinsic toughening (i.e. 3Y) were expected to be more vulnerable to cyclic degradation. However, surprisingly, the extent of cyclic degradation ( $\sim 5 \%$ loss in $\left.\mathrm{K}_{\mathrm{I} 0}\right)$ was rather similar between the different samples. This similar susceptibility to cyclic fatigue in the three zirconia ceramics points out that the transformation toughening (in $3 \mathrm{Y}$ and $4 \mathrm{Y}$ ) is not degraded by cyclic fatigue, since transformation toughening acts as inelastic zones surrounding the crack tip but not behind the crack tip like bridging [38]. The observed cyclic degradation can be attributed to the grain bridging mechanism, i.e. elastic or frictional bridging of contact shielding that can be degraded 
by loading/unloading $[14,38,39,53]$. Even though, as discussed above that grain bridging for the studied zirconia ceramics is only effective in a limited extent and thus cyclic effects solely contribute to a very small proportion of overall degradation as compared to chemically-assisted SCG. From the aspect of threshold, chemically-assisted SCG presented about 50\% reduction of the fracture toughness for zirconia ceramics $\left(\mathrm{K}_{\mathrm{I} 0 \text {,static }} / \mathrm{K}_{\mathrm{IC}} \sim 0.5\right)$, but the cyclic loading gave rise to $\leq 5 \%$

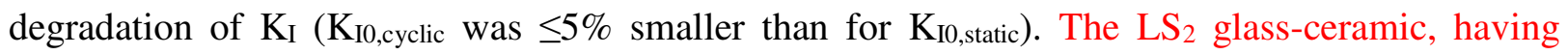
elongated crystals in the order of $2 \mu \mathrm{m}$, suffers more from the cyclic fatigue effect due to the higher dependence of its bridging mechanism on the friction effect at also a larger scale (Fig. 6). Furthermore, the volume fraction of these elongated crystals together with their size, aspect ratio, orientation are critical for the fracture resistance of the $\mathrm{LS}_{2}$ glass-ceramic $[41,54]$, raising the question about the influences of these factors on the SCG and cyclic fatigue of $\mathrm{LS}_{2}$ glass-ceramic for further investigations as well.

Above all, the three zirconia ceramics showed a similar SCG relative susceptibility under both static and cyclic loadings, but were more resistant to SCG than $\mathrm{LS}_{2}$ due to the higher susceptibility of the glass phase to the water-assisted stress-corrosion reaction. Previous studies using indirect methods (dynamic and cyclic fatigue tests) also showed that $\mathrm{LS}_{2}$ glass ceramic would degrade faster over time with smaller $\mathrm{n}$ values than zirconia $[13,55]$ as well as in aqueous environment [11]. In fact, glass-containing ceramics, including glass-infiltrated ceramics, generally exhibited a higher susceptibility to SCG than polycrystalline ceramics (zirconia, alumina) [13, 55-57]. One exception was reported for a leucite-reinforced glass ceramic that contained even 50-60\% aluminosilicate glass (IPS Empress, Ivoclar Vivadent) [13]. Different from $\mathrm{LS}_{2}$ glass ceramic, the enhanced SCG resistance in IPS Empress was attributed to the compressive residual stress developed around the leucite crystals $[13,40]$. 
It is necessary to point out that the current work was performed in ambient air conditions ( 50\% RH) but not in water or body fluid, because water molecules in air were enough for SCG to proceed and only one stage (stage I) would be present in water with the same stress-corrosion coefficient (i.e. the same SCG susceptibility) and with the same threshold stress intensity factor $\mathrm{K}_{\mathrm{I} 0}$ (only different crack growth rate) $[20,58]$. Nevertheless, the oral cavity is a complex environment with a fluctuating temperature, high acidic environment (low $\mathrm{pH}$ ), bacteria and so on. This environment can especially be important for $\mathrm{LS}_{2}$, because $\mathrm{LS}_{2}$ shows a relatively high dissolution in an acidic environment (Fig. $\mathrm{S} 3$ in the supplementary document) and the $\mathrm{V}-\mathrm{K}_{\mathrm{I}}$ diagram in an environment where the materials undergo some dissolution, could be substantially different [59]. Although zirconia ceramics (3Y, $4 \mathrm{Y}$ and 5Y) are quite resistant to acid etching (Fig. S3 in supplementary documents), considering the hydrothermal aging behavior, it is also paramount to study the crack-growth behavior of zirconia ceramics in a more hostile environment more closely resembling the oral cavity, or after a prolonged duration in such media.

\subsection{Material selection based on strength and translucency}

Considering the numerous zirconia ceramics introduced in the dental field and the fact that the mechanical and optical properties of different zirconia ceramics are highly variable, as discussed above, it is interesting to plot a flexural strength versus translucency map (the main parameters commonly employed as guidance to select the proper material to design and fabricate FDPs). Fig. 7 displays a scatter plot of flexural strength versus translucency for various materials that can be processed by CAD-CAM. More detail of the material classification and consulted data sources can be found in the supplementary Fig. S1 and Table S1. Admittedly, the strength is influenced by process conditions (pressing, pre- and sintering) with different flaw sizes and distributions, surface treatments (ground, polished or as-sintered) [60], specimen dimensions and methodologies of 
bending tests with different effective stressed volume [61]. Size limitations of many commercial CAD/CAM materials also lead to the fact that no single sample dimension and test method are dominantly used. The influence of surface treatments especially for zirconia ceramics is also a topic of ongoing investigation [60]. Therefore, in addition to the property of materials themselves, all above mentioned experimental and sampling uncertainties could contribute to increase the scatter of strength data.

Zirconia, both TZP and PSZ, remain in general less translucent than lithium-(di)silicate glass ceramic. TZP here refers to 3Y-TZP in order to be consistent with the commonly used terminology and PSZ refers to zirconia containing yttria contents higher than 3Y. In fact, it should be kept in mind, and this is again shown in the experimental results provided that all yttria-doped zirconia polycrystalline ceramics, with 3-6 mol\% yttria are in fact a mixture of $t$ - and $c-\mathrm{ZrO}_{2}$ (Table 1) [29], thus are all PSZ materials. The evolution of the different zirconia generations from various 'TZPs' to so-called 'PSZ' (sometimes even called not correctly 'cubic zirconia') clearly shows the significant improvement in zirconia's translucency (Fig. S2).

In spite of the reflection at the surfaces, the main factor limiting the light transmission of polycrystalline ceramics is scattering by birefringence at the grain boundary and by pores or second phases [8]. The first generation of dental 3Y-TZP in general contains $0.25 \mathrm{wt} \%$ alumina, allowing some light transmission but as previously introduced, the formation of alumina particles limits their translucency [10]. Then, lower alumina additions (up to as low as $0.05 \mathrm{wt} \%$ ) to zirconia have been suggested. The alumina addition of less than $0.2 \mathrm{wt} \%$ is within the solubility limit of alumina in zirconia and can thus be fully dissolved and segregated as $\mathrm{Al}^{3+}$ at the zirconia grain boundaries [62, 63]. In this way, the zirconia ceramics can still be easily fully-dense sintered with the aid of $\mathrm{Al}^{3+}$ [64] while the formation of secondary alumina particles is avoided (Fig. 2). Furthermore, as shown in Fig. S2b and by previous works [10], decreasing alumina does not significantly compromise 
strength, but slightly lowers hydrothermal aging resistance $[9,10]$. More recently, zirconia is being stabilized with higher yttria contents to obtain even higher translucency (Fig. 3) by decreasing the grain boundary birefringence (higher content of optically isotropic cubic phase and lower birefringence of the remaining tetragonal phase with smaller c/a tetragonality, Table 1) $[9,10,65]$. Some of the new so-called 'high-translucent' PSZ already present light transmission similar to that of $\mathrm{LS}_{2}$ with a low translucency ('LT') or medium opacity ('MO'). A part of the window in the map is indeed also filled by these new zirconia ceramics (Fig. 7, Fig.S2 and Fig. S1). Therefore, with the development of high-translucent zirconia, more indications in fixed prosthodontics can be covered by monolithic restorations.

\section{Conclusions}

Despite the common understanding that increasing yttria content decreases toughening in yttriastabilized zirconia ceramics and thus reduces $\mathrm{K}_{\mathrm{IC}}$ and $\mathrm{K}_{\mathrm{I}}, 5 \mathrm{Y}$ and $4 \mathrm{Y}$ PSZs with a higher translucency are promising materials to be used for monolithic restorations. In view of strength versus translucency map, these new translucent zirconia ceramics can fill a part of the material's window between conventional 3Y-TZP and $\mathrm{LS}_{2}$ glass ceramic, even if the lower Weibull moduli measured require attention in terms of reliability issues.

All investigated zirconia ceramics showed a similar relative susceptibility to static and cyclic SCG with a parallel shift of $\mathrm{V}-\mathrm{K}_{\mathrm{I}}$ curves. Cyclic fatigue degradation was significant, but modest for the four ceramics investigated and was not influenced by the transformation toughening effect. $\mathrm{LS}_{2}$ glass-ceramic was less SCG-resistant than zirconia ceramics, due to its susceptibility to chemicallyassisted stress corrosion. However, $\mathrm{LS}_{2}$ with pronounced extrinsic toughening mechanism from crack bridging exhibited a higher Weibull modulus than 5Y, despite they showed a similar fracture toughness. 


\section{Acknowledgements}

A large portion of the work was performed in the framework of the SISCERA project funded by the European Union's Horizon 2020 Research and Innovation Framework Programme - Fast Track to Innovation Pilot (FTIPilot2016-1) - under Grant Agreement No. 737954. F. Zhang thanks the support of the Research Foundation Flanders (FWO Vlaanderen), who awarded her a post-doctoral fellowship (12S8418N) during the time the manuscript was written. We thank Ivoclar Vivadent for providing the IPS e.max CAD samples (HT, A2/B40 L), PhD student Evita Willems and Prof. Jef Vleugels (both from KU Leuven) for preparing some zirconia samples, and Prof. Marleen Peumans (KU Leuven) for the translucency measurements.

\section{References}

[1] C. Piconi, G. Maccauro, Zirconia as a ceramic biomaterial, Biomaterials 20(1) (1999) 1-25.

[2] I. Denry, J.R. Kelly, State of the art of zirconia for dental applications, Dental Materials 24(3) (2008) 299-307.

[3] T. Miyazaki, T. Nakamura, H. Matsumura, S. Ban, T. Kobayashi, Current status of zirconia restoration, Journal of prosthodontic research 57(4) (2013) 236-261.

[4] S.K. Makhija, N.C. Lawson, G.H. Gilbert, M.S. Litaker, J.A. McClelland, D.R. Louis, V.V. Gordan, D.J. Pihlstrom, C. Meyerowitz, R. Mungia, M.S. McCracken, Dentist material selection for single-unit crowns: Findings from the National Dental Practice-Based Research Network, Journal of dentistry 55 (2016) 40-47. [5] J.R. Kelly, Ceramics in restorative and prosthetic dentistry, Annual Review of Materials Science 27(1) (1997) 443-468.

[6] Y.M. Chen, R.J. Smales, K.H. Yip, W.J. Sung, Translucency and biaxial flexural strength of four ceramic core materials, Dental Materials 24(11) (2008) 1506-11.

[7] Y. Zhang, B.R. Lawn, Novel Zirconia Materials in Dentistry, Journal of dental research 97(2) (2018) 140147.

[8] Y. Zhang, Making yttria-stabilized tetragonal zirconia translucent, Dental Materials 30(10) (2014) 11951203.

[9] E. Camposilvan, R. Leone, L. Gremillard, R. Sorrentino, F. Zarone, M. Ferrari, J. Chevalier, Aging resistance, mechanical properties and translucency of different yttria-stabilized zirconia ceramics for monolithic dental crown applications, Dental materials : official publication of the Academy of Dental Materials 34(6) (2018) 879-890.

[10] F. Zhang, M. Inokoshi, M. Batuk, J. Hadermann, I. Naert, B. Van Meerbeek, J. Vleugels, Strength, toughness and aging stability of highly-translucent $\mathrm{Y}$-TZP ceramics for dental restorations, Dental Materials 32(12) (2016) e327-e337. 
[11] A.R. Studart, F. Filser, P. Kocher, H. Luthy, L.J. Gauckler, Cyclic fatigue in water of veneer-framework composites for all-ceramic dental bridges, Dental materials : official publication of the Academy of Dental Materials 23(2) (2007) 177-85.

[12] J.R. Kelly, P.F. Cesar, S.S. Scherrer, A. Della Bona, R. van Noort, M. Tholey, A. Vichi, U. Lohbauer, ADM guidance-ceramics: Fatigue principles and testing, Dental materials : official publication of the Academy of Dental Materials 33(11) (2017) 1192-1204.

[13] M. Wendler, R. Belli, D. Valladares, A. Petschelt, U. Lohbauer, Chairside CAD/CAM materials. Part 3: Cyclic fatigue parameters and lifetime predictions, Dental materials : official publication of the Academy of Dental Materials 34(6) (2018) 910-921.

[14] R.O. Ritchie, Mechanisms of fatigue-crack propagation in ductile and brittle solids, International Journal of Fracture 100(1) (1999) 55-83.

[15] T. Fett, D. Munz, Ceramics : mechanical properties, failure behaviour, materials selection, Berlin : Springer1999.

[16] A.R. Studart, F. Filser, P. Kocher, L.J. Gauckler, Fatigue of zirconia under cyclic loading in water and its implications for the design of dental bridges, Dental Materials 23(1) (2007) 106-114.

[17] A.R. Studart, F. Filser, P. Kocher, L.J. Gauckler, In vitro lifetime of dental ceramics under cyclic loading in water, Biomaterials 28(17) (2007) 2695-2705.

[18] J. Chevalier, C. Olagnon, G. Fantozzi, Subcritical Crack Propagation in 3Y-TZP Ceramics: Static and Cyclic Fatigue, Journal of the American Ceramic Society 82(11) (1999) 3129-3138.

[19] A.H. De Aza, J. Chevalier, G. Fantozzi, M. Schehl, R. Torrecillas, Crack growth resistance of alumina, zirconia and zirconia toughened alumina ceramics for joint prostheses, Biomaterials 23(3) (2002) 937-945.

[20] B. Lawn, Fracture of Brittle Solids, second Edition Cambridge: Cambridge University Press 1993.

[21] J.J. Kruzic, J.A. Arsecularatne, C.B. Tanaka, M.J. Hoffman, P.F. Cesar, Recent advances in understanding the fatigue and wear behavior of dental composites and ceramics, Journal of the mechanical behavior of biomedical materials 88 (2018) 504-533.

[22] Y. Zhang, I. Sailer, B.R. Lawn, Fatigue of dental ceramics, Journal of dentistry 41(12) (2013) 1135-47.

[23] I. Yamashita, K. Tsukuma, Phase separation and hydrothermal degradation of 3 mol\% $\mathrm{Y}_{2} \mathrm{O}_{3}-\mathrm{ZrO}_{2}$ ceramics, Journal of the Ceramic Society of Japan 113(1320) (2005) 530-533.

[24] I.R. Gibson, J.T.S. Irvine, Qualitative X-ray Diffraction Analysis of Metastable Tetragonal ( $t^{\prime}$ ) Zirconia, Journal of the American Ceramic Society 84(3) (2001) 615-618.

[25] J. Chevalier, M. Saadaoui, C. Olagnon, G. Fantozzi, Double-torsion testing a 3Y-TZP ceramic, Ceramics International 22(2) (1996) 171-177.

[26] A. Shyam, E. Lara-Curzio, The double-torsion testing technique for determination of fracture toughness and slow crack growth behavior of materials: A review, Journal of Materials Science 41(13) (2006) 4093-4104.

[27] T.H. Becker, T.J. Marrow, R.B. Tait, An Evaluation of the Double Torsion Technique, Experimental Mechanics 51(9) (2011) 1511-1526.

[28] D. Williams, A. Evans, A Simple Method for Studying Slow Crack Growth, ASTM International (1973) 264-270.

[29] J.A. Krogstad, M. Lepple, Y. Gao, D.M. Lipkin, C.G. Levi, Effect of Yttria Content on the Zirconia Unit Cell Parameters, Journal of the American Ceramic Society 94(12) (2011) 4548-4555.

[30] M.H. Bocanegra-Bernal, S.D. de la Torre, Phase transitions in zirconium dioxide and related materials for high performance engineering ceramics, Journal of Materials Science 37(23) (2002) 4947-4971.

[31] M. Wendler, R. Belli, A. Petschelt, D. Mevec, W. Harrer, T. Lube, R. Danzer, U. Lohbauer, Chairside CAD/CAM materials. Part 2: Flexural strength testing, Dental materials : official publication of the Academy of Dental Materials 33(1) (2017) 99-109.

[32] J. Yan, M.R. Kaizer, Y. Zhang, Load-bearing capacity of lithium disilicate and ultra-translucent zirconias, Journal of the mechanical behavior of biomedical materials 88 (2018) 170-175. 
[33] M.E. Ebrahimi, J. Chevalier, G. Fantozzi, Slow crack-growth behavior of alumina ceramics, Journal of Materials Research 15(1) (2000) 142-147.

[34] C.J. Gilbert, J.J. Cao, W.J. Moberlychan, L.C. DeJonghe, R.O. Ritchie, Cyclic fatigue and resistance-curve behavior of anin situ toughened silicon carbide with AIBC additions, Acta Materialia 44(8) (1996) 31993214.

[35] R.H. Dauskardt, M.R. James, J.R. Porter, R.O. Ritchie, Cyclic Fatigue-Crack Growth in a SiC-WhiskerReinforced Alumina Ceramic Composite: Long- and Small-Crack Behavior, Journal of the American Ceramic Society 75(4) (1992) 759-771.

[36] L.M. E., R.R. O., On the Fracture Toughness of Advanced Materials, Advanced Materials 21(20) (2009) 2103-2110.

[37] R.H.J. Hannink, P.M. Kelly, B.C. Muddle, Transformation Toughening in Zirconia-Containing Ceramics, Journal of the American Ceramic Society 83(3) (2000) 461-487.

[38] R. Steinbrech, Toughening mechanisms for ceramic materials, Journal of the European Ceramic Society 10(3) (1992) 131-142.

[39] C. Gilbert, R. Dauskardt, R. Ritchie, Microstructural mechanisms of cyclic fatigue-crack propagation in grain-bridging ceramics, Ceramics International 23(5) (1997) 413-418.

[40] E. Apel, J. Deubener, A. Bernard, M. Höland, R. Müller, H. Kappert, V. Rheinberger, W. Höland, Phenomena and mechanisms of crack propagation in glass-ceramics, Journal of the mechanical behavior of biomedical materials 1(4) (2008) 313-325.

[41] R. Belli, M. Wendler, M.R. Cicconi, D. de Ligny, A. Petschelt, K. Werbach, H. Peterlik, U. Lohbauer, Fracture anisotropy in texturized lithium disilicate glass-ceramics, Journal of Non-Crystalline Solids 481 (2018) 457-469.

[42] A.A. Griffith, The phenomena of rupture and flow in solids, Philosophical Transactions 221 (1920) 163-198.

[43] Y. Ju-Won, L. Chung-Jae, L. Myung-Gu, Effect of Coloring Agent on the Strength and Transmittance of Dental Zirconia Block, Int J Clin Prev Dent 13(4) (2017) 223-230.

[44] M. Inokoshi, F. Zhang, K. Vanmeensel, J. De Munck, S. Minakuchi, I. Naert, J. Vleugels, B. Van Meerbeek, Residual compressive surface stress increases the bending strength of dental zirconia, Dental Materials 33(4) (2017) e147-e154.

[45] T.A. Sulaiman, A.A. Abdulmajeed, K. Shahramian, L. Lassila, Effect of different treatments on the flexural strength of fully versus partially stabilized monolithic zirconia, The Journal of prosthetic dentistry 118(2) (2017) 216-220.

[46] B. Stawarczyk, A. Liebermann, M. Eichberger, J.F. Guth, Evaluation of mechanical and optical behavior of current esthetic dental restorative CAD/CAM composites, Journal of the mechanical behavior of biomedical materials 55 (2015) 1-11.

[47] S.E. Elsaka, A.M. Elnaghy, Mechanical properties of zirconia reinforced lithium silicate glass-ceramic, Dental materials : official publication of the Academy of Dental Materials 32(7) (2016) 908-14.

[48] R. Fabian Fonzar, M. Carrabba, M. Sedda, M. Ferrari, C. Goracci, A. Vichi, Flexural resistance of heatpressed and CAD-CAM lithium disilicate with different translucencies, Dental materials : official publication of the Academy of Dental Materials 33(1) (2017) 63-70.

[49] J. Chevalier, L. Gremillard, A.V. Virkar, D.R. Clarke, The Tetragonal-Monoclinic Transformation in Zirconia: Lessons Learned and Future Trends, Journal of the American Ceramic Society 92(9) (2009) 19011920.

[50] K. Yoshida, F. Wakai, N. Nishiyama, R. Sekine, Y. Shinoda, T. Akatsu, T. Nagoshi, M. Sone, Large increase in fracture resistance of stishovite with crack extension less than one micrometer, Scientific Reports 5 (2015) 10993.

[51] J. Chevalier, C. Olagnon, G. Fantozzi, Crack propagation and fatigue in zirconia-based composites, Composites Part A: Applied Science and Manufacturing 30(4) (1999) 525-530. 
[52] S.M. Wiederhorn, Influence of Water Vapor on Crack Propagation in Soda-Lime Glass, Journal of the American Ceramic Society 50(8) (1967) 407-414.

[53] R.H. Dauskardt, A frictional-wear mechanism for fatigue-crack growth in grain bridging ceramics, Acta Metallurgica et Materialia 41(9) (1993) 2765-2781.

[54] F.C. Serbena, I. Mathias, C.E. Foerster, E.D. Zanotto, Crystallization toughening of a model glassceramic, Acta Materialia 86 (2015) 216-228.

[55] Y. Zhang, B. Lawn, Long-term strength of ceramics for biomedical applications, Journal of Biomedical Materials Research Part B: Applied Biomaterials 69B(2) (2004) 166-172.

[56] J. Tinschert, G. Natt, N. Mohrbotter, H. Spiekermann, K.A. Schulze, Lifetime of alumina- and zirconia ceramics used for crown and bridge restorations, Journal of biomedical materials research. Part B, Applied biomaterials 80(2) (2007) 317-21.

[57] M. Borba, M.D. de Araujo, K.A. Fukushima, H.N. Yoshimura, P.F. Cesar, J.A. Griggs, A. Della Bona, Effect of the microstructure on the lifetime of dental ceramics, Dental materials : official publication of the Academy of Dental Materials 27(7) (2011) 710-21.

[58] C. Olagnon, J. Chevalier, V. Pauchard, Global description of crack propagation in ceramics, Journal of the European Ceramic Society 26(15) (2006) 3051-3059.

[59] M.V. Swain, Impact of oral fluids on dental ceramics: What is the clinical relevance?, Dental Materials 30(1) (2014) 33-42.

[60] T. Kosmač, C. Oblak, P. Jevnikar, N. Funduk, L. Marion, The effect of surface grinding and sandblasting on flexural strength and reliability of Y-TZP zirconia ceramic, Dental Materials 15(6) (1999) 426-433.

[61] R. Danzer, T. Lube, P. Supancic, R. Damani, Fracture of Ceramics, Advanced Engineering Materials 10(4) (2008) 275-298.

[62] F. Zhang, K. Vanmeensel, M. Inokoshi, M. Batuk, J. Hadermann, B. Van Meerbeek, I. Naert, J. Vleugels, Critical influence of alumina content on the low temperature degradation of 2-3mol\% yttria-stabilized TZP for dental restorations, Journal of the European Ceramic Society 35(2) (2015) 741-750.

[63] K. Matsui, Grain-boundary structure and microstructure development mechanism in 2-8mol\% yttriastabilized zirconia polycrystals, Acta Materialia 56(6) (2008) 1315-1325.

[64] K. Matsui, N. Ohmichi, M. Ohgai, N. Enomoto, J. Hojo, Sintering Kinetics at Constant Rates of Heating: Effect of Al2O3 on the Initial Sintering Stage of Fine Zirconia Powder, Journal of the American Ceramic Society 88(12) (2005) 3346-3352.

[65] J. Klimke, M. Trunec, A. Krell, Transparent Tetragonal Yttria-Stabilized Zirconia Ceramics: Influence of Scattering Caused by Birefringence, Journal of the American Ceramic Society 94(6) (2011) 1850-1858. 
(a)

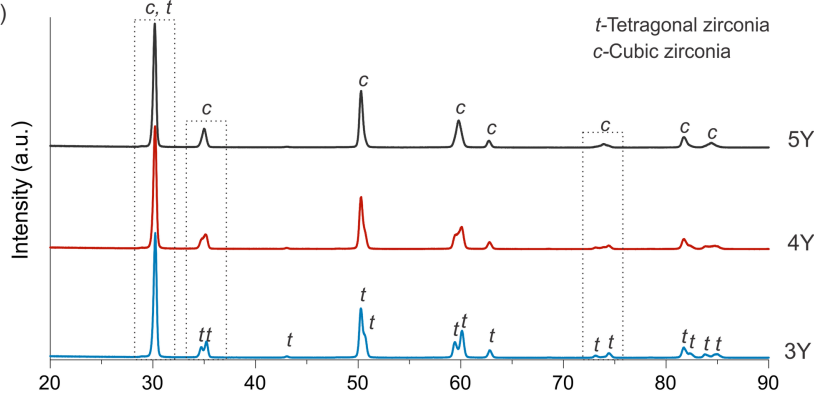

(b)
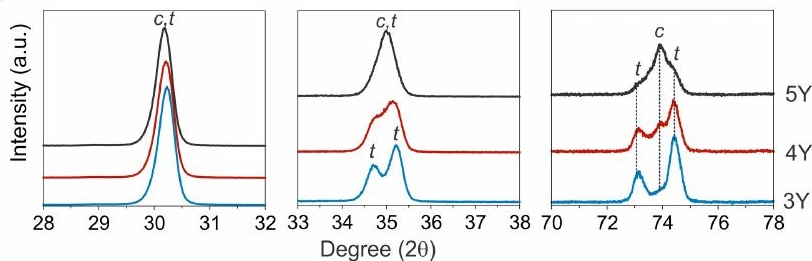
Degree $(2 \theta)$

$t$-Tetragonal zirconia c-Cubic zirconia

$4 Y$

Y

$Y$ 

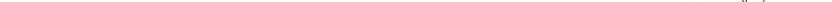


\section{Contrast ratio/CR}

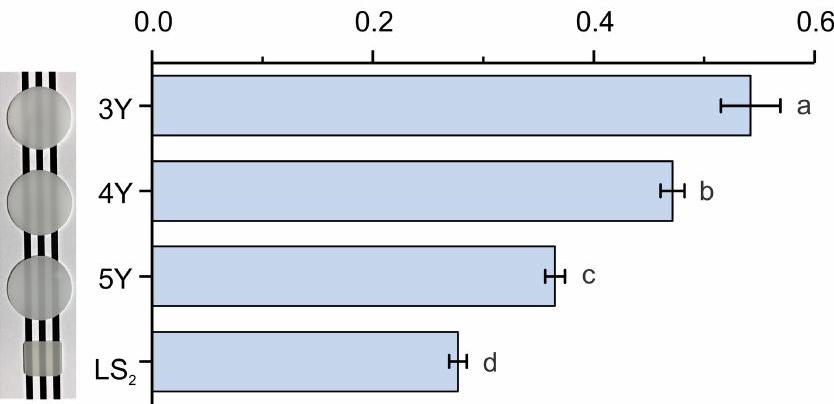




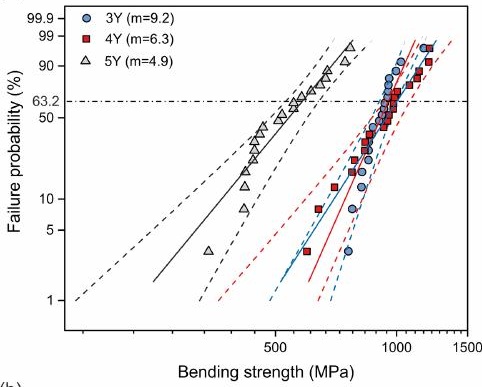

(b)
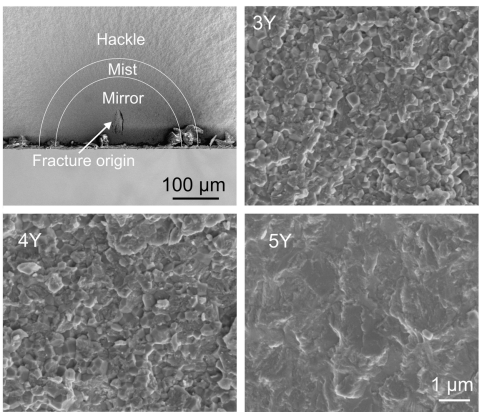

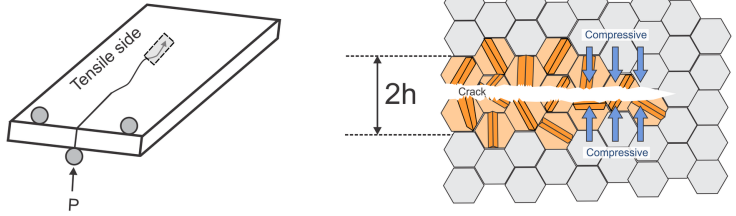

\section{$3 Y$}




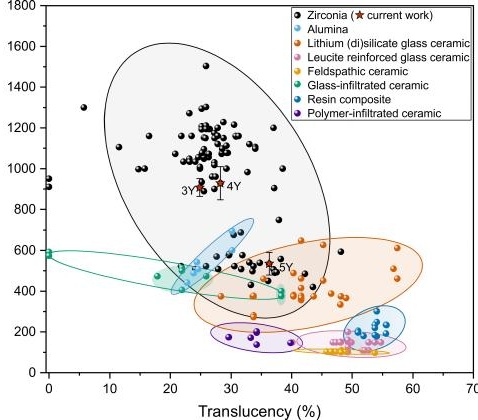


Tables:

Table 1. Phase composition and lattice parameters using XRD and Rietveld analysis.

\begin{tabular}{cccccc}
\hline & & & $3 \mathrm{Y}$ & $4 \mathrm{Y}$ & $5 \mathrm{Y}$ \\
\hline \multirow{3}{*}{$\mathrm{XRD}$} & & & & & \\
& Traction $(\%)$ & $87 \pm 2$ & $63 \pm 4$ & $42 \pm 4$ \\
& & $c / a$ & $1.0151 \pm 0.0002$ & $1.0147 \pm 0.0000$ & $1.0126 \pm 0.0007$ \\
\cline { 2 - 6 } & & $\mathrm{Y}_{2} \mathrm{O}_{3}(\mathrm{~mol} \%)$ & $2.7 \pm 0.06$ & $2.9 \pm 0.01$ & $3.7 \pm 0.30$ \\
\hline \multirow{2}{*}{ Cubic } & fraction (\%) & $13 \pm 2$ & $37 \pm 4$ & $58 \pm 4$ \\
& & $c(\AA)$ & $5.1379 \pm 0.0005$ & $5.1360 \pm 0.0007$ & $5.1348 \pm 0.0001$ \\
\hline
\end{tabular}

Table 2. Grain size, translucency and strength of all ceramics investigated. Mean values are reported with ( \pm ) $95 \%$ confidence interval.

\begin{tabular}{|c|c|c|c|c|c|}
\hline & \multirow{2}{*}{ Grain size $(\mu \mathrm{m})$} & \multicolumn{2}{|c|}{ Translucency (CR) } & \multicolumn{2}{|c|}{ 4-point bending strength } \\
\hline & & $1.0 \mathrm{~mm}$ & $0.5 \mathrm{~mm}$ & Average (MPa) & Weibull modulus \\
\hline $3 Y$ & $0.30 \pm 0.01^{\mathrm{a}}$ & $0.65 \pm 0.02^{\mathrm{a}}$ & $0.54 \pm 0.02^{\mathrm{c}}$ & $908 \pm 44^{\mathrm{a}}$ & 9.2 \\
\hline $4 Y$ & $0.36 \pm 0.02^{b}$ & $0.59 \pm 0.01^{b}$ & $0.47 \pm 0.01^{\mathrm{d}}$ & $928 \pm 82^{a}$ & 6.3 \\
\hline $5 Y$ & $0.53 \pm 0.03^{\mathrm{c}}$ & $0.45 \pm 0.00^{\mathrm{d}}$ & $0.36 \pm 0.01^{\mathrm{e}}$ & $534 \pm 56^{b}$ & 4.9 \\
\hline $\mathrm{LS}_{2}$ & $\begin{array}{c}1.72 \pm 0.12(\mathrm{~L}) \\
4.06 \pm 0.36 \text { (aspect ratio) }\end{array}$ & - & $0.28 \pm 0.01^{f *}$ & $462 \pm 15^{\#}$ & $10.0^{\#}$ \\
\hline
\end{tabular}

Different superscripts (for each variable) indicate statistically different results (significance level $\alpha=0.05$ ); ${ }^{*} \mathrm{LS}_{2}$ is HT, high translucency grade; " Value reported by Wendler et al. (2017) using the same 4-point bending test [31].

Table 3. SCG parameter values.

\begin{tabular}{cccccccc}
\hline & & \multicolumn{3}{c}{ SCG Static } & \multicolumn{3}{c}{ SCG cyclic $(10 \mathrm{~Hz}, \mathrm{R}=0.1)$} \\
\cline { 3 - 8 } & $\left(\mathrm{MPa} \cdot \mathrm{m}^{1 / 2}\right)$ & $\begin{array}{c}\mathrm{K}_{\mathrm{I} 0} \\
\left(\mathrm{MPa} \cdot \mathrm{m}^{1 / 2}\right)\end{array}$ & $\mathrm{K}_{\mathrm{I} /} / \mathrm{K}_{\mathrm{IC}}$ & $\mathrm{n}$, stage I & $\begin{array}{c}\mathrm{K}_{\mathrm{I} 0} \\
\left(\mathrm{MPa} \cdot \mathrm{m}^{1 / 2}\right)\end{array}$ & $\mathrm{K}_{\mathrm{I} 0} / \mathrm{K}_{\mathrm{IC}}$ & n, stage I \\
\hline $3 \mathrm{Y}$ & $5.0 \pm 0.3$ & $2.7 \pm 0.1$ & 0.54 & $30.8 \pm 7.2$ & 2.5 & 0.49 & 20.9 \\
$4 \mathrm{Y}$ & $4.0 \pm 0.2$ & $2.2 \pm 0.1$ & 0.55 & $27.7 \pm 5.5$ & 2.1 & 0.52 & 17.9 \\
$5 \mathrm{Y}$ & $3.3 \pm 0.2$ & $1.5 \pm 0.1$ & 0.46 & $27.2 \pm 3.2$ & 1.4 & 0.43 & 23.7 \\
$\mathrm{LS}_{2}$ & $3.1 \pm 0.2$ & $1.1 \pm 0.1$ & 0.35 & $15.8 \pm 5.5$ & 1.0 & 0.32 & 10.5 \\
\hline
\end{tabular}

